\title{
X Jornades Científiques Mataró
}

\author{
Maria Tura Puigverd (tura.puigvert@gmail.com) Associació de professors de Física i Química de Catalunya
}

Les X Jornades Científiques de Mataró van tenir lloc els passats dies 12 i 13 d'abril de 2013. El programa detallat de les Jornades i els formularis d'inscripció en línia a la mostra de treballs de recerca i a la gimcana científica estan disponibles des del 13 de març en aquest espai web: https://sites.google.com/site/jornadescientifiquesmataro/

Fa més de deu anys, quan els treballs de recerca dels batxillerats començaven a donar els seus fruits, molts professors sentíem la necessitat de fer quelcom per difondre la cultura científica a la ciutadania i per donar a conèixer els bons treballs de recerca que, amb l'esforç de professors i alumnes, es feien a tots els centres de batxillerat. Era una etapa de canvi de rumb en l'ensenyament de les ciències, moment en què els professors $\mathrm{i}$ professores havíem après com és d'important la comprensió pública de la ciència i enteníem la necessitat d'alfabetitzar en ciències tota la població escolar, no d'adoctrinar en lleis científiques com si es tractés d'un ensinistrament per a futurs treballadors de laboratori. Les Jornades Científiques de Badalona varen obrir camí en el tema de la presentació pública de treballs de recerca i un grup de professors de Mataró, desitjosos de promoure la difusió de cultura científica en la ciutat, vàrem voler adaptar aquell model a les nostres possibilitats $\mathrm{i}$ inquietuds.

Des del primer moment, el grup de treball format per professorat de ciències de centres de secundària de Mataró hem treballat sota l'aixopluc - suport institucional, recursos humans i recursos econòmics- del Centre de Recursos Pedagògics del Departament d'Ensenyament de la Generalitat de Catalunya i de l'Institut Municipal d'Educació de l'Ajuntament de Mataró. Actualment també hi col-laboren altres entitats públiques i privades: TecnoCampus Mataró, CETEMSA, Associació de professors de física i química de Catalunya, Aigües Mataró, etc.

En aquests deu anys hem mantingut l'esquema bàsic següent:

Divendres a la tarda, Mostra de treballs de recerca - dos treballs representatius de cada centre - precedida d'una conferència magistral d'interès general per a la ciutadania - canvi climàtic, els transgènics, l'aigua d'ús domèstic a Mataró, el tub verd, etc. - a la qual hi són convidats els pares, familiars $\mathrm{i}$ amics dels alumnes que presenten els seus treballs a la mostra. És una manera de comunicar ciència més enllà dels centres escolars $i$ fer que arribi als ciutadans una mostra sobre com s'entén actualment la ciència, més propera als problemes reals i allunyada de les visions dogmàtiques dels antics llibres de text.

Dissabte a la tarda, Fira de difusió de la ciència en llocs del centre de Mataró on hi sol haver gent passejant i gaudint del cap de setmana. Els primers anys només cercàvem fer explicacions senzilles a partir de muntatges espectaculars (ascensions en un globus captiu, espectacle de formació de bombolles, mostra de llançament de coets, etc.) i després ja vàrem evolucionar cap a muntar amb els nostres recursos la fira de la ciència, que ha consistit en un conjunt d'experiments acompanyats d'explicacions senzilles i que cada any s'ha centrat en un tema diferent. A partir de la cinquena edició vàrem incorporar la Gimcana científica per a grups de joves i alhora també hem anat convidant a entitats locals que volen divulgar diversos aspectes de la ciència: Tecnocampus de Mataró, CETEMSA, Aigües Mataró, etc.

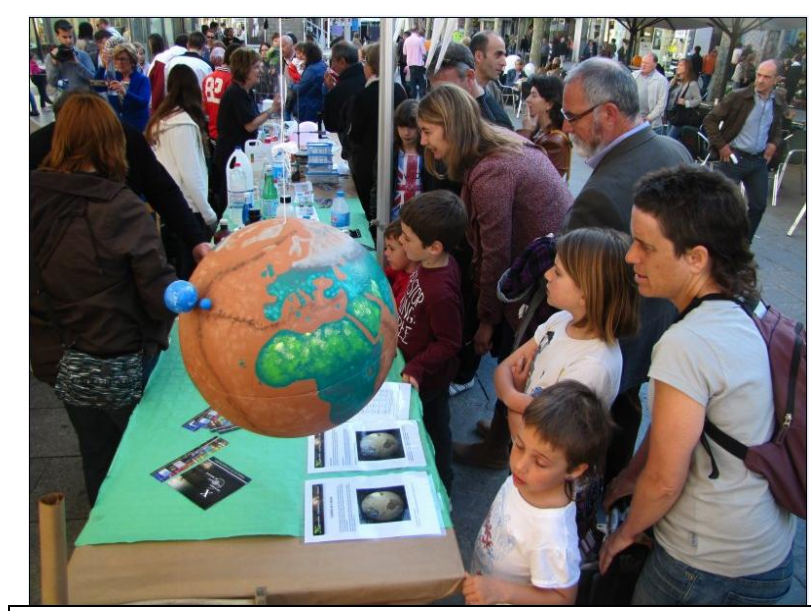

Figura 1. Fira al carrer. 
En els experiments de la fira ens han ajudat grups d'alumnes de secundària i en el conjunt de les Jornades científiques hi han intervingut tots els centres de secundària de Mataró i alguns instituts de la comarca com I'INS Bisbe Sivilla de Calella, I'INS Vilatzara de Vilassar de Mar.

Estem contents d'haver celebrat les X Jornades científiques de Mataró. Malgrat totes les contrarietats i amb un pressupost molt reduït, hem volgut que ressoni la celebració de les $\mathrm{X}$ Jornades científiques de Mataró i ens ha sortit prou bé.

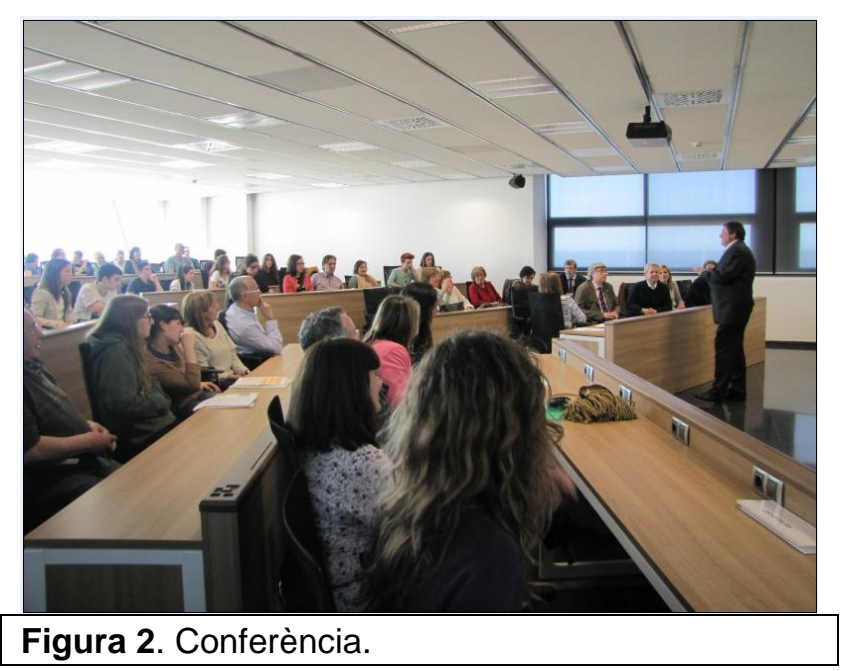

En aquests últims anys, l'entorn social, l'ambient de treball, la predisposició institucional, tot està una mica enrarit, i ens ha costat un xic més planificar amb il-lusió, con si no passés res. La meteorologia sí que ens va acompanyar. Va ser un d'aquells dies de primavera tan lluminosos, en què la gent passeja amb la cara alegra i amb ganes de comunicar-se. Els menuts encuriosits, com sempre, i els grans amb ganes d'explicar-los i explicar-se un munt de preguntes que es feien en aturar-se en les nostres barraquetes, tots gaudíem veient els experiments i escoltant-nos les explicacions.

Desitgem que manifestacions d'aquesta mena, que ja n'hi ha un bon nombre en tot el país, vagin proliferant $i$ evolucionant cap a llenguatges que afavoreixin la cultura general de tothom.

\section{Presència de les $X$ Jornades científiques de Mataró als mitjans de comunicació:}

Enllaç a la notícia de televisió de Mataró M1tv: http://m1tv.xiptv.cat/24-hores-maresmenoticies/capitol/surten-al-carrer-les-jornadescientifiques-de-mataro

Enllaç a la notícia de la revista Tot Mataró, digital i imprès:

http://www.totmataro.cat/portal//index.php?optio n=com_content\&task=view\&id=99746\&ltemid $=38$ https://sites.google.com/site/jcm10anysepositori/elt ot_1575_pag63.pdf

Enllaç al reportatge de l'emissora Mataró Ràdio: https://sites.google.com/site/jcm10anysepositori/ 10jc_mataroradio.mp3

Enllaç al Butlletí de l'Ajuntament de Mataró: https://serveisweb.mataro.cat/web/portal/conting ut/noticia/2013/04/10894_Jornades_cientifiques.ht $\mathrm{ml}$ 